\title{
Social Justice Praxis within the Walls to Bridges Program: Pedagogy of Oppressed Federally Sentenced Women Rachel Fayter
}

\section{INTRODUCTION}

Based on my personal experiences with the Walls to Bridges (W2B) program (formerly Inside-Out Canada), I have found a renewed value and meaning in education while incarcerated and I argue that the W2B program is an example of social justice praxis. Furthermore, my involvement with the $\mathrm{W} 2 \mathrm{~B}$ program has transformed my carceral experience from one that is oppressive to feeling empowered and valued as a person. Additionally, I have been able to maintain an ongoing and meaningful connection with the community through my involvement with the program.

I begin this paper by providing a brief overview of W2B, including my experience with the program. Next, I connect literature concerning three distinct forms of oppression; namely, dehumanization/objectification, disempowerment and self-depreciation, as well as the importance of social intervention to personal experience. Thirdly, I integrate relevant literature with reflections on my own experiences to highlight W2B's commitment to three key themes: transformational education, social justice, and maintaining a sense of community and connection. Finally, I briefly outline several key barriers to education in prison to illustrate some of the challenges and limitations of the W2B program.

\section{BRIEF OVERVIEW OF THE WALLS TO BRIDGES PROGRAM}

The W2B program began in Canada in 2009, stemming from the U.S. based Inside-Out Prison Exchange Program. However, there are important and interesting differences between Inside-Out and W2B. As an instructor, trainer and steering committee member, Dr. Simone Davis brought InsideOut to Canada in 2009. A partnership was developed between Peter Stuart, a correctional educator and guidance counsellor at Grand Valley Institution for Women (GVI) and Dr. Shoshana Pollack of the Faculty of Social Work at Wilfrid Laurier University (WLU), who has worked with criminalized women in Canada for over 25 years. Shoshana took the U.S. Inside-Out training during the summer of 2011 and with the support of 
Peter Stuart and each of their respective institutions, was able to offer a course at GVI that fall.

Walls to Bridges courses connect campus-enrolled and incarcerated or criminalized students in the community together as classmates, using an egalitarian circle pedagogy that emphasizes respectful dialogue, experiential learning, and shared inquiry. In a "circle of trust" we speak our own truth, while listening receptively to the truth of others, using simple personal testimony without affirming or negating other speakers (Palmer, 2004). The Canadian W2B approach utilizes Frierian principles, Indigenous pedagogy, decolonizing and intersectional analysis, and critical, feminist, anti-racist practices. W2B facilitators and students develop shared learning opportunities that disrupt hierarchies, challenge assumptions, and create deep connections (W2B Training Manual, 2016).

The first Inside-Out course at GVI was offered by WLU with ten "outside" social work students and seven "inside" students. The class met weekly at GVI for one semester to explore issues in a course entitled "Diversity, Marginalization, and Oppression". The student alumni from this first class became the founding members of the Walls to Bridges Collective (W2BC). This group has met twice monthly at GVI since its inception. In 2014, a Toronto chapter of the W2BC formed to allow people getting out of prison to stay connected to the work of W2B while living in the community. Both groups welcome new alumni and collaborate and support each other to deliver facilitator training, public education workshops and forums, and to implement participatory action research projects (W2B Training Manual, 2016).

I enrolled in my first W2B course in September 2014, taking "Diversity, Marginalization, and Oppression" with Dr. Shoshana Pollack. Upon completing the course, I immediately applied to become a member of the collective. In September 2015, I participated in my second W2B class entitled "Equity in Education" with Dr. Jasmin Zine. As an active member of the collective, I have assisted with the planning, implementation and facilitation of two five-day instructor training sessions during the summers of 2015 and 2016. We also facilitated a Decent Work Forum at GVI in April 2016 in which approximately 120 participants, including about 40 community members, engaged in critical dialogue to discuss solutions concerning employment issues confronted by criminalized women. The background context of W2B provides a general basis for the program's values, goals and overall pedagogical approach. 


\section{OPPRESSION WITHIN THE INSTITUTION AND EMPOWERING SOLUTIONS}

In this section, I reflect upon the dehumanizing aspects of oppression to which I am subject inside. Secondly, I consider how interventions stemming from the interests of the oppressors maintain the hierarchical and repressive status quo. Thirdly, I briefly examine the necessity of engaging in a dialogue with the oppressed that respects human rights while recognizing social privilege in order to engage in critical and humane interventions.

In my first W2B course we read a chapter from Paulo Freire's (2003) Pedagogy of the Oppressed and spent time unpacking the concepts within a small group. Freire's discussion of oppressive acts as dehumanizing stood out and pushed me to reflect on my personal experiences of incarceration within the Canadian legal system. Although I had read Freire's Pedagogy of the Oppressed several times in the past, through the W2B, I developed new insights and understood his analysis of oppression from the perspective of the oppressed for the first time. Freire outlines several dehumanizing aspects of oppression that revealed the overwhelming power of Correctional Service Canada (CSC) and demonstrated the degrading aspects of incarceration for me. It was extremely unsettling to identify so clearly with Freire's description of oppressed people and to reflect on the power of the oppressor.

Freire (2003, pp. 56-57) asserts that "an act is oppressive only when it prevents people from being more fully human". From my perspective, the entire experience of incarceration prevents people from being more fully human. We are forced through a confusing and unjust system in which verdicts are influenced by money, power, and various lawyers' interpretations of the law. Everything we know and love is taken from us; we are separated from our families, friends, and communities; we are herded like cattle, numbered and counted like economic products, and locked up like wild animals. Furthermore, Freire (2003, p. 60) explains how "the oppressed, as objects, as things, have no purposes except those their oppressors prescribe for them". Everything we say and do is recorded by our handlers, and used to classify and place us. We are seen as 'inmates' (rather than citizens), known primarily by our Fingerprint Section (FPS) number and do what those in power believe is best for us. We have no voice, no choice and no identity outside that of "criminal". Correctional officials tell us when to eat, sleep, go outside and take our medicine. They control who we can call, visit with and write to. 
Access to proper and timely health, medical, and dental care is challenging and inconsistent. Completion of a high school education is forced, while postsecondary education is difficult to access, and institutional jobs are assigned based on the decision of the security personnel, rather than the supervising staff or the qualifications of the person.

Another dehumanizing consequence of incarceration that illustrates its' oppressive nature is self-depreciation. According to Freire (2003, p. 63), "self-depreciation is another characteristic of the oppressed, derived from their internalization of the oppressors' opinion". I have been labelled an 'addict', 'drug dealer', 'criminal', 'inmate' and 'convict', and a 'danger to the community' by guards, parole officers, and others within the criminal justice and correctional system. Many people I know have been called much worse. Eventually, we begin to view ourselves through this lens. CSC discourse claims that corrections can empower women in prison. However, for me, the W2B class is the single most humanizing and empowering aspect of my incarceration, replacing these negative labels and stereotypes with positive ones.

In a recent study on the impacts of the W2B program at Grand Valley Institution for Women (GVI), researchers found that one of the key outcomes of taking a W2B course was the interpersonal relationships made between two groups of students who are normally unlikely to meet one another (Pollack, 2016). The relational connections and educational approach of W2B were identified as central to the process of becoming aware of and eliminating stereotypes that could prevent authentic connections between inside and outside students. As I re-read Freire (2003), incorporating my newfound perspectives and insights, I felt angry, frustrated and powerless. As a federal prisoner, I have encountered oppression more significantly than any other time in my life.

Social interventions are necessary for oppressed and marginalized groups who experience social injustice, inequality, and lack access to various needed resources - all characteristics of incarcerated people. However, according to Freire (2003), any form of education or intervention for the oppressed should be developed in partnership with the oppressed group, stemming from their needs and interests. The implementation of a liberating education that starts from the interests and perceptions of those in power is shrouded in the false generosity of paternalism; it maintains and embodies oppression and is an instrument of dehumanization (Freire, 2003). The W2B program is 
conducted in full partnership with both inside and outside alumni, including collective members who were previously incarcerated. Everyone involved in the W2B collective, which oversees the educational program, has a voice and is able to contribute to virtually every aspect of the program.

Choules (2007) identifies several long-term negative social consequences for people who are seen as the "objects" of charitable action or intervention, including loss of dignity and powerlessness. In this framing, those with power take up the benevolent and potentially condescending role of protector, while the oppressed group is constituted as in need of protection, yet lacking the capacity to take care of themselves. The objects of charity are expected to respond with gratitude and often become dependent on the charitable actions. Choules (2007) further argues that a charitable approach tends to be patronizing and paternalistic, and rarely remedies the underlying needs of oppressed people.

As I read these arguments from Freire (2003) and Choules (2007), I immediately thought of my experience within the correctional system. As a federally sentenced woman, I am required to take a minimum of three programs that CSC deems necessary for my rehabilitation and successful reintegration into the community. There are certainly some beneficial aspects to these programs, such as encouraging women to examine harmful thoughts and actions that lead to criminal behaviour. That said, my experience within these CSC programs is diametrically opposed to my experiences with the W2B program. Much of the CSC course content focuses on pointing out our individual deficiencies, which are positioned as the reasons why we committed a crime and teaches us how to become "pro-social" people. For example, CSC defines a risk factor as an individual characteristic that leads one to engage in problematic or criminal behaviour. With the intent of encouraging "accountability", social, economic, familial and environmental factors are disregarded in correctional conceptualizations of risk. Thus, the underlying structural oppressions - which form the basis of our needs - are ignored. We are told that there is never an excuse for committing a crime. If we attempt to explain our actions and the reasons for them, we are told that we are engaging in "techniques of neutralization", which Sykes and Matza (1957) describe as the discursive methods through which individuals justify their delinquent or illegal actions. CSC program facilitators inform us that we always have a choice, even if that choice means starving, being homeless or dying. We are told these choices are always preferable to committing a 
crime. As I reflect on the social justice readings and my experience within CSC programs, I continue to feel angry, frustrated, and powerless. These programs do not explore issues of marginalization, diversity, oppression or inequality - and they were not developed or evaluated with input from their intended beneficiaries.

The current prison system in Canada is like a revolving door for people living in poverty and those who are struggling with addiction or mental health issues; this is particularly the case for individuals from racialized and Indigenous communities. Prisoners receive clothing, food and shelter while all the external social problems are overlooked. Rather than working on eliminating poverty, homelessness, inequality and social disparity in Canada, the federal government spends more money on walls, fences, and guards for our prisons. In fact, according to CSC, critiquing unjust social policies is a specific technique of neutralization that they describe as "blaming the system" (WOMIP Training Manual, 2014). The mandatory correctional programs do not examine structural oppressions, focusing exclusively on encouraging prisoners to embrace personal responsibility for their marginalization. As a result, the criminal justice system maintains the status quo and dissuades the oppressed from critiquing the system so as to prevent the oppressors from losing their power. Those in power are concerned with ensuring "the people continue in a state of submersion, impotent in the face of oppressive reality" (Freire, 2003, p. 52). This is also consistent with Freire's assertion that the oppressed lack confidence in themselves; believing in the invulnerability and power of the oppressor. By asserting their power, focusing on our individual deficits, and offering paternalistic charity, CSC breeds complacency in federally sentenced women. Women in prison often give up their personal and legal rights and freedoms, simply because many of us do not believe we can win against the system. We are threatened with segregation, losing our jobs, a higher security classification, no parole, no visits home, and other serious consequences; so we are scared to fight back. Despite these barriers, there is hope for change; it is possible to resist and even overcome oppression.

I assert that one way of battling oppression within the Canadian prison system is through strong, collaborative educational programs, such as W2B, that are transformative for the students involved and built on a foundation of social justice. The W2B class format and overall program structure is based on key principles from Freire's Pedagogy of the Oppressed. Freire 
(2003) explains that this pedagogy requires the involvement of people engaged in the fight for their own liberation, who recognize themselves as oppressed. Consciousness-raising or a dialogue with people facing oppression is necessary for change. The oppressed must be subjects in their struggle, not objects. The W2B program allows inside students to have this dialogue in a safe space, free of CSC staff, in solidarity with people who might actually hear us. According to Freire (2003, p. 68), "the only effective instrument is a humanizing pedagogy in which the revolutionary leadership establishes a permanent relationship of dialogue with the oppressed". Additionally, respecting human rights can potentially lead to radical social change. Choules (2007) argues that social injustice could be eliminated if human rights were completely embraced. However, she also cautions us to recognize the impact of social privilege. Those who occupy positions of power must be challenged for their role in perpetuating social injustice by maintaining their power and privilege. This is the value of a W2B classroom; it actively seeks to level the playing field by using circle pedagogy to reduce traditional academic, social and economic hierarchies. Considering consciousness-raising as social intervention helped to mitigate my feelings of anger and powerlessness, and filled me with hope to change our archaic and oppressive prison system.

\section{COLLABORATIVE LEARNING: TRANSFORMATION, SOCIAL JUSTICE AND COMMUNITY CONNECTIONS}

I believe that my participation in the W2B program is an exercise in social justice praxis. The program is committed to transformative education, social justice and maintaining a sense of community. In what follows, I use liberatory, critical, and transformative pedagogical literature to reflect on my experiences within the W2B classroom and collective to illustrate this point. Furthermore, I demonstrate how W2B's pedagogical approach and experiential learning activities are directly linked to meeting and maintaining certain human rights.

\section{Transformative Qualities of W2B}

Education alone can be transformative and liberating for people in prison, where loneliness and degradation are common in an atmosphere permeated 
by contention and distrust (Perry, 2013). Gaining an education provides prisoners with a sense of hope, purpose, and strength while giving them the knowledge and skills to succeed in the community. This in turn enables opportunities for further education and career aspirations once released. The pedagogical model that both W2B and the Inside-Out Prison Exchange Program pursue goes one step further in transforming traditional Western approaches to education, thus having the potential to transform the prison, university and overall community. W2B and Inside-Out pedagogies both do away with the one-way transmission of information that typically characterizes learning environments and, as a result, eliminate hierarchy where students also become teachers. This model requires all students to be active participants, rather than passive recipients of information. By being active in one's education, the student is more likely to become invested (Turenne, 2013). These pedagogical practices analyze and reject structures of oppression, injustice, and inequality while empowering the voices of those who are commonly silenced and marginalized (Perry, 2013). This innovative course format allows students to traverse boundaries between the university and prison, boundaries that have been created and enforced by a culture of law and order. Crossing boundaries is the engine of transformation (Bumiller, 2013).

Based on interviews with students who took a one-semester W2B course, Pollack (2016) found transformative impacts on the students' sense of self as a result of their participation in the program. Students spoke about the positive impacts on their self-esteem, sense of belonging, family relationships, personal agency, attitudes and behaviour. From my own experience with the program, I felt an increase in my self-esteem: I felt like I belonged, was valued and was heard for the first time since my incarceration. For me, involvement in the classroom offers a break from typical prison life. When participating in the class and collective, I feel like an intelligent, valuable and thoughtful individual who is able to express herself freely, without fear of repercussion. I am appreciated for my opinion, my voice is heard and I am a valued subject in the class. Freely choosing to participate in the program, I have an identity outside of the labels prescribed to me by CSC.

According to Allred and colleagues (2013), feelings of transformation and confidence contribute to one's capacity to handle life's opportunities and challenges. In a W2B course, transformation stems from the relational learning experience, which shifts the focus from the potential for individual 
change to a collaborative understanding of more complex social issues that are constructed through respectful and sustained engagements with the professor and fellow classmates (Allred et al., 2013).

The W2B program includes people from diverse cultural, racial and social backgrounds with very different life experiences. By learning to transcend these differences we learn that people are fundamentally alike. Dynamics regarding race, gender, class, age, sexuality, and other differences within the classroom are not ignored, but are instead worked through in a collective and authentic manner (Turenne, 2013). Honouring one another's identities requires trust and openness as students bring their personal truths into the circle conversation. Students identify circle pedagogy and learning from each other's diverse life experiences as leading to personal growth that extends beyond the classroom context (Pollack, 2016). This pedagogical model provides concrete evidence that through individual and collective effort we can transform society into a safer and more egalitarian place to live (Perry, 2013).

The classroom is structured with all of the "inside" and "outside" students, the teaching assistant and professor sitting in a circle formation, so that no one person is perceived as having more power or knowledge than another. This circle format also allows for every person in the room to have an opportunity to speak from their own experience and truth. No single perspective is seen as more accurate or valuable than another (Palmer, 2004). The circle allows everyone to have a voice and gives the space and time for each person to share their story or perspective. This is especially important for marginalized people who may rarely have had the opportunity to be heard. Pollack (2016) explains how the concept of "finding a voice" was a repetitive theme throughout the interviews she conducted with W2B students. Interview participants noted that the ability to be oneself in the classroom and to discuss one's lived experiences with their peers using the analytical framework of the course was transformative.

This exercise of sharing our stories and being heard is directly linked to Freire's (2003) calls for consciousness-raising and generating a dialogue with the oppressed. The circle format is both effective and humanizing, which Freire states are essential aspects for progressive social change. Similarly, Choules (2007) claims that respecting and embracing human rights can potentially lead to radical social transformation. The circle format does not allow for debating any students' perspective truth or censoring 
one's opinion. Instead, we are encouraged to voice our thoughts and beliefs, while listening receptively and respectfully to one another. Therefore, one of our fundamental freedoms guaranteed in the Canadian Charter of Rights and Freedoms (CCRF, 1982) is being exercised: our "freedom of thought, belief opinion and expression" (article 2B). Similarly, in Choules' (2007) critique of charity, she argues that those in power are the furthest from the reality of those with need. The circle format allows oppressed federally sentenced women to share and express their material experiences with each other. This simple activity within the class is our only opportunity to speak openly and freely about our beliefs and experiences while incarcerated.

\section{Commitment to Social Justice and Human Rights}

In one W2B course, we read articles related to social justice and the class participated in an activity where four pieces of chart paper were posted around the room. We were invited to envision a utopian society that is built on social justice principles within four areas: education, employment, social and mental health services, and the criminal justice system. We had an opportunity to move freely around the room writing our uncensored ideas under the relevant headings on the chart paper. Afterwards, these documents were shared and discussed as a class. I have participated in similar visioning activities before, but I found this particular exercise to be especially empowering. I felt engaged, excited, and invigorated with hope because despite being oppressed within the prison system, my voice was being respected and heard.

Based on my description of the chart exercise, it is clear that this activity aligns with the CCRF (1982). The United Nations (UN) Universal Declaration of Human Rights (1948), Article 26 also outlines the right to education and is especially relevant to my learning experiences facilitated via the circle format and the chart exercise. According to the UN Human Rights treaty, education should be "directed to the full development of the human personality and the strengthening of respect for human rights and fundamental freedoms. It shall promote understanding, tolerance, and friendship among all nations, racial or religious groups ... for the maintenance of peace". Sharing our stories and truly listening to one another without judgement, while working together as a class to envision a socially just society are both examples of an education based on key human rights principles.

A central aspect of Freire's (2003) Pedagogy of the Oppressed concerns the oppressed person's consciousness, specifically their view of the world and 
their ethics. Beginning a dialogue with the oppressed person or group can help to challenge the oppressed consciousness in order to engage them in the fight for liberation. According to bell hooks (1994), engaging in dialogue is one of the easiest ways we can begin as teachers, students and critical thinkers to cross boundaries. W2B courses offer unique opportunities for dialogue and leadership development among diverse students. Such opportunities facilitate a paradigm shift in thinking about crime and social justice, potentially leading to social change (Bumiller, 2013). Respectful dialogue leads to understanding others; W2B courses facilitate this through small group work and projects, which transforms into action as students learn to work across differences, to agree and disagree without resentment, and to collaborate more effectively. These skills can ripple out to the larger community, potentially reducing stereotypes and discrimination. Ideally, this can alter society's perceptions of, and response to, various inequalities and harmful ideological practices (Turenne, 2013).

Social justice is promoted within the W2B classroom as power relations are overcome when made transparent (Carines, 2013). Outside students can glimpse into the lived realities of the inside students, while inside students interact with academic material in unique and interesting ways, and have discussions on social justice issues with engaged community members. Outside students often experience a radical change in the way they view incarcerated individuals as they learn to challenge dominant stereotypes about criminalized people (Perry, 2013). W2B course content and the process of creating a community cultivate a sense of personal accountability and commitment from both inside and outside students to challenge social inequalities (Pollack, 2016).

The W2B collective of alumni from the program is an example of how community-based learning can evolve into a deeper, long-term commitment to collaborate on social justice issues. There are currently eight Inside-Out "think-tanks" in the United States and two W2B circles or collectives in Canada (Pompa, 2013). Outside student alumni often join the collective so they can maintain their connection to W2B. Collective projects related to social justice can help to intensify civic engagement and promote interest in these issues amongst the general public through workshops and events. The Inside-Out think-tanks and W2B collectives encourage the pursuit of higher education among inside students, while facilitating the development of personal agency and social activism, and empowering members to create change. Many members and program alumni have taken leadership roles in 
diverse social justice initiatives (Perry, 2013). As an inside student, I have experienced a renewed sense of hope in my ability to complete my graduate studies and contribute to social action. I plan on using this oppressive experience to advocate for prisoners' rights in the future.

\section{Maintaining a Sense of Community and Connection}

As students transform their relationships with and work together in the pursuit of social justice, a sense of community develops. Pollack (2016) reported that students often used the word "community" to refer to a sense of accountability, interconnectedness and shared purpose that they believed developed through class interactions. Utilizing circle pedagogy builds a sense of community (Palmer, 2004), while small group work and projects also assists in fostering community. As students work together towards a common goal they must compromise, and be patient and empathetic (Turenne, 2013). In contrast to the feelings of alienation and loneliness that prisoners often experience, W2B students recognize each other as fully human and develop skills to connect with others, which can help to combat emotional isolation. In effect, the program structure aims to build relationships and a greater sense of humanity amongst students (Harris, 2013).

\section{BARRIERS TO SECURING AN EDUCATION WHILE IN PRISON}

While there are many benefits that flow from the W2B program structure, it is also important to contextualize the barriers and challenges that make it difficult and impossible for some to secure an education while incarcerated. The barriers to education that exist in prison are physical, institutional, relational and psychological in nature. The following is meant to provide a brief snapshot of some of the main challenges faced by women accessing education programs in prison.

\section{Physical Barriers}

\section{Limited Access to Computers}

Incarcerated students do not have access to computers in their living unit. Students can access classroom computers only during those hours when movement throughout the institution is permitted and when the classrooms 
are not in use. During evenings and weekends, she must rely on the guards to open the room. There is no Internet access, which restricts our ability to conduct research, obtain articles and books, or complete college or university correspondence courses, since most are only available online.

\section{Lockdowns}

Management will lockdown the institution for various "security" reasons, forcing people in custody to remain in their living units, cancelling all programs and not allowing outside visitors into the prison. These lockdowns can last anywhere from a matter of hours to days or even weeks. A lockdown can result in missed classes and W2B collective meetings, which we are often unable to make-up. During lockdowns, incarcerated students cannot access computers and cannot speak to other inside students or teaching assistants.

\section{Institutional Barriers}

\section{Lack of Resources}

The computers that are available to incarcerated students have outdated hardware and software. The prison library is relatively small with very limited hours and minimal academic materials. The focus of CSC's education policies is with the completion of high school, therefore postsecondary education is given second priority.

\section{Financial}

Fortunately, W2B courses and the required course materials are offered free of charge to inside students. It is extremely difficult to pursue additional postsecondary programs since people in custody have virtually no income and cannot access a scholarship that is available to students in the community, not to mention the fact that there are a very limited number of bursaries available.

\section{Relational Barriers}

\section{Interpersonal Conflict}

Due to the location and nature of the W2B course, conflict can enter the classroom more easily than in a traditional setting, preventing or damaging 
group cohesiveness, if not mediated by the facilitator. Unlike taking classes on a college campus, in prison we are locked in a very small, restricted, oppressive community in which solidarity is punished and frowned upon.

\section{Power Imbalances}

Although differences in power are present everywhere in society, and clearly within the university setting, yet they are especially salient in the prison context. As prisoners, we are constantly oppressed and discriminated against. Our voice, choices and actions are consistently monitored, judged, and restricted. It is extremely challenging to succeed in this environment. Many women find it difficult to participate in class and express their views on paper because prison is not a safe environment in which to speak out.

\section{Psychological Impacts}

\section{High Stress Environment}

It is not easy to focus on academic work in the oppressive, stressful environment of a prison. Along with being separated from our friends and family, communities, and nature, we experience constant instability. The policies and procedures of the prison are enforced inconsistently depending on the guards' mood, who is working, or which prisoner is being targeted. There are frequent house and room searches in which items can be seized, misplaced, or destroyed. We also lack privacy and often do not have a quiet place to work.

These barriers, along with the oppressive environment, cause many prisoners to feel powerless, unmotivated, and hopeless at times. Simply reading course materials or completing a written assignment requires an inside student to surmount obstacles that outside students may not imagine exist. Additionally, we face some of the same barriers that outside students' experience, such as personal/family issues, health problems, or mental health issues, yet we do not have the same access to social and practical supports.

\section{CONCLUSION}

Education can facilitate the process of empowerment for many individuals. For marginalized people within an oppressive institution, education has the 
potential to change lives. Specifically, the W2B program is an example of social justice praxis because it has the ability to facilitate transformation at the individual, relational and community levels for people experiencing oppression. The program's circle pedagogical approach alters traditional Western models of education by disrupting hierarchies, utilizing experiential learning approaches, integrating one's whole self into the learning experience and encouraging marginalized people to have a voice. Furthermore, the W2B program fosters a commitment to social justice and builds a sense of community among participants, while creating and maintaining community connections for incarcerated students. Although there are many barriers to education in prison, based on my personal experience, I argue that the W2B pedagogy and the meaningful relationships it facilitates are an effective way to overcome these barriers, transform people's lives, and empower women. These positive impacts can ripple out from the classroom, to the prison and, finally, the wider community.

\section{REFERENCES}

Allred, Sarah, Nathan Belche and Todd Robinson (2013) "Relational Learning and the Inside-out Experience: A Pathway to Building Capacities, Transformative Perspectives, and a Deeper Understanding of Self, Community, and Others", in Simone Weil Davis and Barbara Sherr Roswell (eds.), Turning Teaching Inside: A Pedagogy of Transformation for Community-based Education, New York: Palgrave Macmillan, pp. 209-226.

Bumiller, Kristin (2013) "Transformative Learning in Prisons and Universities: Reflections on Homologies of Institutional Power", in Simone Weil Davis and Barbara Sherr Roswell (eds.), Turning Teaching Inside Out: A Pedagogy of Transformation for Community-based Education, New York: Palgrave Macmillan, pp. 177-186.

Carines, Mario (2013) "Full Circle: A Journey from Students to Trainers", Simone Weil Davis and Barbara Sherr Roswell (eds.), Turning Teaching Inside Out: A Pedagogy of Transformation for Community-based Education, New York: Palgrave Macmillan, pp. 83-91.

Choules, Kathryn (2007) "The Shifting Sands of Social Justice Discourse: From Situating the Problem with "Them" to Situating it with "Us"', Review of Education, Pedagogy, and Cultural Studies, 29: 461-481.

Freire, Paulo (2003) Pedagogy of the Oppressed, New York: The Continuum International Publishing Group.

Harris, M. Kay (2013) "Inside-out: What the World Needs Now", in Simone Weil Davis and Barbara Sherr Roswell (eds.), Turning Teaching Inside Out: A Pedagogy of Transformation for Community-based Education, New York: Palgrave Macmillan, pp. 49-62. 
hooks, bell (1994) Teaching to Transgress: Education as the Practice of Freedom, New York: Routledge.

Palmer, Parker (2004) A Hidden Wholeness: The Journey Toward an Undivided Life, San Francisco: Jossey-Bass.

Perry, Paul (2013) "Death of a Street-gang Warrior", in Simone Weil Davis and Barbara Sherr Roswell (eds.), Turning Teaching Inside Out: A Pedagogy of Transformation for Community-based Education, New York: Palgrave Macmillan, pp. 35-48.

Pollack, Shoshana (2016) Walls to Bridges: Report on the Impact on Students, Waterloo $(\mathrm{ON})$ : Wilfrid Laurier University.

Pompa, Lori (2013) "Drawing forth, finding voice, making change: Inside-out learning as transformative pedagogy", in Simone Weil Davis and Barbara Sherr Roswell (eds.), Turning Teaching Inside Out: A Pedagogy of Transformation for Communitybased Education, New York: Palgrave Macmillan, pp. 27-31.

Sykes, Gresham and David Matza (1957) "Techniques of Neutralization", American Sociological Review 22(6): 664-670.

Turenne, Ella (2013). "Breaking through 'isms"”, in Simone Weil Davis and Barbara Sherr Roswell (eds.), Turning Teaching Inside Out: A Pedagogy of Transformation for Community-based Education, New York: Palgrave Macmillan, pp. 121-130.

United Nations (1948) Universal Declaration of Human Rights.

WOMIP Training Manual (2014) Woman Offender Moderate Intensity Intervention Program Training Manual, Ottawa: Correctional Services Canada.

\section{ABOUT THE AUTHOR}

Rachel Fayter is a 35-year-old single woman currently incarcerated at Grand Valley Institution in Kitchener, Ontario. She has been actively involved in the Walls to Bridges program as a student and collective member since September 2014. Rachel was born in Toronto and moved around often with her parents as a child. She attended Wilfrid Laurier University for over ten years, earning her BA in Psychology in 2004 and her MA in Community Psychology in 2006. She completed most of her coursework for a $\mathrm{PhD}$ in Community Psychology prior to her incarceration. Rachel has done extensive work in both community and research settings with troubled children and youth, and homeless adults grappling with mental health issues. Following her release, she hopes to complete her $\mathrm{PhD}$ in the same or a related field, as well as continue her work with social activism and community engagement, focusing on advocating for prisoner rights. 